\title{
The Role of Different Inflammatory Indices in the Diagnosis of COVID-19
}

\author{
Marwa Eissa (iD) ${ }^{1,2}$ \\ Sabry Shaarawy ${ }^{3}$ \\ Mona S Abdellateif (iD ${ }^{3}$ \\ 'Internal Medicine and Endocrinology \\ Department, Faculty of Medicine, Cairo \\ University, Cairo, Egypt; ${ }^{2}$ Endocrinology \\ Department, Faculty of Armed Forces of \\ Medical College (AFMC), Cairo, Egypt; \\ ${ }^{3}$ Medical Biochemistry and Molecular \\ Biology, Cancer Biology Department, \\ National Cancer Institute, Cairo \\ University, Cairo, Egypt
}

\begin{abstract}
Aim: To assess the role of different inflammatory indices in the diagnosis of COVID-19 infection.

Methods: The neutrophil-to-lymphocyte ratio (NLR), lymphocyte-to-monocyte ratio (LMR), platelet-to-lymphocyte ratio (PLR), derived NLR (dNLR), neutrophil to lymphocyte, platelet ratio (NLPR), systemic inflammation index (SII), aggregate index of systemic inflammation (AISI), systemic inflammation response index (SIRI) and C-reactive proteinto-lymphocyte ratio (CRP/L) were assessed in 88 COVID-19 patients compared to 41 healthy control subjects.

Results: The NLR, PLR, NLPR, SIRI, and CRP/L were significantly increased, while LMR was significantly decreased in COVID-19 patients compared to the control group $(\mathrm{P}=0.008$, $0.011,<0.001,0.032,0.002$ and $\mathrm{P}<0.001$; respectively). The AUC for the assessed indices was LMR (0.738, P = 0.008), NLPR (0.721, P $<0.001), \mathrm{CRP} / \mathrm{L}(0.692, \mathrm{P}=0.002)$, NLR (0.649, $\mathrm{P}<0.001)$, PLR (0.643, $\mathrm{P}=0.011)$, SIRI $(0.623, \mathrm{P}=0.032)$, dNLR $(0.590, \mathrm{P}=$ $0.111)$, SII $(0.571, \mathrm{P}=0.207)$, and AISI $(0.567, \mathrm{P}-0.244)$. Multivariate analysis showed that NLPR $>0.011$ (OR: 38.751, $\mathrm{P}=0.014)$, and $\mathrm{CRP} / \mathrm{L}>7.6(\mathrm{OR}: 7.604, \mathrm{P}=0.022$ ) are possible independent diagnostic factors for COVID-19 infection.
\end{abstract}

Conclusion: NLPR and CRP/L could be potential independent diagnostic factors for COVID-19 infection.

Keywords: COVID-19, C-reactive protein, lymphocytes, inflammatory index, platelets, SII

\section{Introduction}

The pandemic of COVID-19 has emerged as a worldwide health problem, as it affected more than three million cases all over the world, and it is responsible for about 200,000 deaths in the period between the end of 2019, till the 28th of April 2020. ${ }^{1}$ The main problem of the SARS-CoV-2 is the high infectivity and the high mortality rate observed in the patients. Its clinical feature varied from asymptomatic and mild one to severe and critical disease which may progress to multi-organ failure and death. ${ }^{2}$

A growing body of evidence explained the clinical and pathological effect of COVID-19 as a hyper-inflammatory response and hyper-cytokinaemia. This hyperinflammatory response leads to microvascular obstructive thrombo-inflammatory syndrome, which results in the presence of underlying endothelial dysfunction, which involves the microvascular bed of vital organs, leading to multiple organ failure and death. ${ }^{3,4}$

Peripheral white blood cell (WBC) count, with its differential subsets including neutrophils, lymphocytes, eosinophils and basophils, are considered useful biomarkers
Correspondence: Mona S Abdellateif Medical Biochemistry and Molecular Biology, Cancer Biology Department, National Cancer Institute, Cairo University, Cairo, II976, Egypt

$\mathrm{Fax}+20223644720$

Email mona.sayed@nci.cu.edu.eg 
for systemic inflammation and immune response. ${ }^{5}$ The neutrophils are an important component of the inflammation response, their regulation is through mast cells, epithelial cells, and macrophages. ${ }^{6}$ Lymphocytes also have an important role in both inflammation and infections. ${ }^{7}$ Additionally, platelets have an important role in haemostasis, coagulation, angiogenesis, innate immunity, and inflammatory reaction. ${ }^{8}$ Thrombocytopenia is found in more than half of the COVID-19 patients and its degree varies according to the disease severity. ${ }^{9}$ Moreover, coagulation dysfunction is also an important risk factor for the adverse outcomes in COVID19 patients. ${ }^{10}$ Therefore, the platelet count and coagulation profile should be considered in managing patients with SARSCoV-2 infection. ${ }^{11}$

Indeed, the CBC parameters either used individually or as their ratios to one another (eg, NLR, LMR, PLR, dNLR, NLPR, SII, AISI, SIRI, and CRP/L) could be used as an index of inflammation and immunity in many diseases and tumors including lung and colorectal cancer. $6,12,13$

The NLR and PLR had been reported to be a useful prognostic factor for COVID-19 severity in several studies. $^{7,14,15}$ Also, the NMR was observed to be associated significantly with pneumonia in COVID-19 patients. ${ }^{14}$ Another recently proposed inflammatory score is the SII, which relies on thrombocyte, neutrophil and lymphocyte count. It was used as a follow-up marker in patients with sepsis as an inflammation index. In addition, it was found to be a good diagnostic marker for COVID19 patients with a sensitivity of $74.9 \%$, and a specificity of $68.9 \%{ }^{16}$ A recently published study done by Fois et $\mathrm{al}^{17}$ concluded that increased AISI, dNLR, NLPR, NLR, SII, and SIRI values associated significantly with increased mortality in SARS-COV-2 patients.

The CRP is an inflammatory marker, synthesized in the liver. It is an acute-phase protein that responds to inflammatory cytokines produced by activated monocytes or macrophages after infection. ${ }^{18}$ It was proposed that the level of CRP reflects the severity of inflammation and consequently the cytokine storm associated with the poor outcome of COVID-19. ${ }^{19,20}$ The CRP/L ratio is an important inflammation marker that was used especially in bacterial infection. Recently, it was found that CRP/L associated significantly with COVID-19 mortality. ${ }^{21}$

The diagnosis of COVID-19 infection is mainly confirmed by the real-time PCR analyses, which proves the presence of the virus. However, this technique is timeconsuming due to the high number of samples, also it is relatively expensive especially in poor communities, so not all patients, particularly suspected cases do it. Therefore, finding easy, simple, cheap and rapid test for early diagnosis is a crucial issue. In this study, we assessed the possibility of using different inflammatory indices, including NLR, LMR, PLR, dNLR, NLPR, SII, AISI, SIRI, and CRP/L in the diagnosis of COVID-19 patients. These indices will provide a fast, accessible, easy to calculate and cheap way for COVID-19 diagnosis relative to the other molecular and radiological methods. So that, it will be applicable in developing countries.

\section{Patients and Methods}

This retrospective cohort study included 88 patients with COVID-19 infection compared to 41 healthy control subjects. Patients who were involved in the study presented to the outpatients' clinic of Kasr Al-Aini hospital, Cairo University during the period between March 2020 and June 2020. All patients were proved to be COVID19 positive based on the molecular, laboratory and radiological findings according to the guidance of WHO. ${ }^{22}$ Most of the presented patients were of mild severity 53 $(59.6 \%)$ with mild symptoms and normal imaging findings. Followed by $29(32.6 \%)$ patients of moderate severity with fever and lung affection by X-ray and CT chest. While only 7 (7.9\%) patients had severe SARSCOV-2 disease with severe respiratory symptoms, respiratory rate $>30 / \mathrm{min}$ and $\mathrm{O}_{2}$ saturation was $<93 \%$ in the rest state. Patients were treated according to the Egyptian National guidelines for COVID-19, and according to guidelines of $\mathrm{WHO}^{22}$ in which mild cases were treated with symptomatic treatment in the form of antipyretics for fever and pain, adequate nutrition and appropriate rehydration. Moderate cases were treated with symptomatic treatment and antibiotics for secondary bacterial infection, with close monitoring for any disease progression. Meanwhile, patients with severe infection required supplemental oxygen administration, intensive care unit admission, secretion clearance and supportive care. In addition to monitoring for complications, such as acute respiratory distress syndrome (ARDS), acute liver injury, acute kidney injury, acute cardiac injury, disseminated intravascular coagulation (DIC) and/or shock.

The study protocol was approved by the institutional review board of the faculty of medicine, Cairo University, which was in concordance with the 2011 Declaration of Helsinki. All recruited subjects approved the publication 
and signed informed consent before enrolment in the study.

The complete blood cell count (CBC)-derived different inflammation indices, as well as different biochemical markers were assessed in the COVID-19 patients and control subjects.

The following inflammatory indices were calculated as follows; NLR (neutrophil/lymphocytes), LMR (lymphocyte/monocyte ratio), PLR (platelet/lymphocyte ratio), dNLR (neutrophils/(white blood cells - neutrophils)), NLPR (neutrophil/(lymphocyte $\times$ platelet ratio)), SII ((neutrophils $\times$ platelets)/lymphocytes), AISI ((neutrophils $\times$ monocytes $\times$ platelets $) /$ lymphocytes $)$, SIRI ((neutrophils $\times$ monocytes)/lymphocytes), and CRP/L (CRP/lymphocyte ratio).

\section{Statistical Analysis}

Data were analysed using the SPSS package (version 22; SPSS Inc., Chicago, IL, USA). It was tested for normalization using Shapiro test. Continuous variables were expressed as median and interquartile range (IQR), while categorical variables were expressed as frequencies and percentages. Comparisons between groups were performed using the Mann-Whitney test and Chi-square test for numerical and categorical variables, respectively. A receiver operating characteristic (ROC) curve analysis was performed to assess the diagnostic value of the inflammatory indices for COVID-19 infection. Univariate and multivariate regression analyses were performed to detect the association of the different parameters assessed with the COVID-19 viral infection. All tests were two-tailed and $\mathrm{P}$-value $<0.05$ was considered statistically significant.

\section{Results}

The median age of the assessed COVID-19 patients was 41 (range; 10-85) years old, and that of the control group was 40 (range; 13-62) years old. Male represented 53.4\% $(47 / 88)$ of the patients, and females were $53.4 \%(41 / 88)$, while in the control group, males were $43.9 \%$ (18/41), and females were $56.1 \%(23 / 41)$. Regarding the laboratory parameter assessed between COVID-19 patients and the control group, there was a significant increase in the hemoglobin concentration $(\mathrm{Hb})$ in COVID-19 patients compared to the control group [12.6 (7-15.9) versus 11.6 (5.9-14.1) g/dl; respectively, $\mathrm{P}=0.039$ ]. The platelet count was significantly decreased in COVID-19 patients [227 (range; 90-448) $\left.\times 10^{9} / \mathrm{L}\right]$ compared to the control group $\left[296.5\right.$ (range; 205-532) $\times 10^{9} / \mathrm{L}, \mathrm{P}=$
0.004]. Similarly, eosinophils were significantly decreased in the COVID-19 patients [0.05 (range; 00.26) $\left.10^{3} / \mathrm{ul}\right]$ compared to the control group $[0.13$ (range; 0.11-0.14) $\left.10^{3} / \mathrm{ul}, \mathrm{P}=0.002\right]$. Lymphopenia was also observed in the COVID-19 patients compared to control group, where lymphocyte count was 1.5 (range; 0.02-4) x $10^{3} / \mathrm{ul}$ in the COVID-19 patients, and it was 2.3 (range; 1.3-3.4) x 103/ul in healthy controls $(\mathrm{P}<$ 0.001). As for relative lymphocyte count, it was 25 (range; 0.25-55.3) $\times 10^{3} / \mathrm{ul}$ in the COVID-19 patients, while it was 35 (range; 6.5-56.7) x 103/ul in the control group $(P=0.007)$. There was a significant increase of C-reactive protein (CRP) in the COVID-19 patients in comparison to the control subjects $[13.1$ (range; $0-$ 337) $\mathrm{mg} / \mathrm{L}$ versus 6 (range; 0-34) $\mathrm{mg} / \mathrm{L}$; respectively, $\mathrm{P}=0.003$ ]. Also, ferritin was significantly increased in the COVID-19 patients compared to the control group [200 (range; 8-1764) ng/L versus 43 (range; 13-1967) ng/L; respectively, $\mathrm{P}=0.008$ ]. Similarly, D-dimer was significantly increased in the COVID-19 patients compared to the control group [0.33 (range; 0.07-4164) ng/ $\mathrm{mL}$ versus 0.1 (range; $0-0.5$ ) ng/mL; respectively, $\mathrm{P}<$ 0.001]. The other laboratory findings of the patients are illustrated in Table 1.

\section{The Results of the Assessed Inflammatory Indices in COVID-19 Patients}

The value of NLR increased significantly in COVID-19 patients $[2.57(0.02-90)]$ in comparison to the control group [1.68 (1-3), $\mathrm{P}=0.008]$. Also, there was a significant increase in the PLR $[146.3(43-12,663)$ and 117.8 (80-197); respectively, $\mathrm{P}=0.011]$, NLPR [0.01 (0-0.36) and $0.003(0.002-0.01)$; respectively, $\mathrm{P}<0.001$ ], SIRI [0.65 (0.01-21.1) and $1.1(0.2-2.1)$; respectively, $\mathrm{P}=0.032]$ and $\mathrm{CRP} / \mathrm{L}[7.6(0-715.8)$ and 2.6 (0.44-15.87); respectively, $\mathrm{P}=0.002]$ in COVID-19 patients compared to the control group, while there was a significant decrease in the LMR in COVID-19 patients compared to the control group [3.6 (0-15) and $6.8(2-8)$; respectively, $\mathrm{P}<0.001]$. However, there was no significant difference between COVID-19 patients and the control group regarding the values of dNLR [1.35 (0.016.69) and 1.26 (0.48-2.45); respectively, $\mathrm{P}=0.111]$, SII [440 (7-22,626) and 738 (145-899); respectively, $\mathrm{P}=$ $0.207]$ and AISI [139.7 (2-5678) and 136.3 (43-1031); respectively, $\mathrm{P}=0.244$, Figure 1]. 
Table I Clinical and Laboratory Findings of the COVID-I9 Patients and Control Group

\begin{tabular}{|c|c|c|c|}
\hline & COVID-19 Patients (n=88) & Control Group $(n=4 I)$ & P value \\
\hline Age & $41(10-85)$ & $40(13-62)$ & 0.103 \\
\hline \multicolumn{4}{|l|}{ Gender } \\
\hline Male & 47 (53.4\%) & 18 (43.9\%) & 0.671 \\
\hline Female & $41(46.6 \%)$ & $23(56.1 \%)$ & \\
\hline \multicolumn{4}{|l|}{ Comorbidities } \\
\hline Negative & $75(85.2 \%)$ & $29(70.7 \%)$ & 0.06 \\
\hline Positive & $13(14.8 \%)$ & $12(29.3 \%)$ & \\
\hline $\mathrm{Hb}(\mathrm{g} / \mathrm{dl})$ & $12.6(7-15.9)$ & II.6 (5.9-I4.I) & 0.039 \\
\hline RBCs $\left(10^{6} / \mathrm{ul}\right)$ & $4.6(2.2-5.9)$ & $4.6(3.1-5.6)$ & 0.601 \\
\hline HCT (\%) & $38.5(21-49.3)$ & $34.8(|9.5-4| .3)$ & $0.08 \mathrm{I}$ \\
\hline MCV (fL) & $82.4(51.5-108)$ & $77.4(56.2-88.3)$ & 0.107 \\
\hline $\mathrm{MCH}(\mathrm{Pg})$ & $27(16.2-34.2)$ & $25.5(18.8-28)$ & 0.051 \\
\hline RDW (fL) & $13.6(12-23)$ & $13.7(12-22)$ & 0.289 \\
\hline Platelets $\left(\times 10^{9} / \mathrm{L}\right)$ & $227(90-448)$ & $296.5(205-532)$ & 0.004 \\
\hline MPV (fL) & $9.2(8-11)$ & $9.7(9-10)$ & 0.355 \\
\hline $\operatorname{TLC}\left(\times 10^{9} / \mathrm{L}\right)$ & $6.5(3.1-14.1)$ & $5.8(5.6-6)$ & 0.873 \\
\hline Neutrophil \% & $57.5(0.64-87)$ & $64.7(32.6-90.2)$ & 0.208 \\
\hline Neutrophil $\left(10^{3} / \mathrm{ul}\right)$ & $2.9(0.04-21.8)$ & $4.4(1.8-9.7)$ & 0.992 \\
\hline Segmented \% & $60(0.56-86.4)$ & $52(45-59)$ & $0.65 I$ \\
\hline Eosinophil $\left(10^{3} / \mathrm{ul}\right)$ & $0.05(0-0.26)$ & $0.13(0.11-0.14)$ & 0.002 \\
\hline Monocyte $\left(10^{3} / \mathrm{ul}\right)$ & $0.38(0-1.6)$ & $0.46(0.36-1.3)$ & 0.318 \\
\hline Basophil (103/ul) & $0(0-0.23)$ & $0(0-0.07)$ & 0.520 \\
\hline Lymphocyte \% & $25(0.25-55.3)$ & $35(6.5-56.7)$ & 0.007 \\
\hline Lymphocytes $\left(10^{3} / \mathrm{ul}\right)$ & $1.5(0.02-4)$ & $2.3(1.3-3.4)$ & $\mathrm{P}<0.001$ \\
\hline CRP (mg/L) & I3.I (0-337) & $6(0-34)$ & 0.003 \\
\hline Ferritin (ng/L) & $200(8-1764)$ & $43(13-1967)$ & 0.008 \\
\hline D-dimer (ng/mL) & $0.33(0.07-4164)$ & $0.1(0-0.5)$ & $P<0.00$ I \\
\hline LDH (U/L) & $282(|4|-\mid 300)$ & $304(165-443)$ & 0.952 \\
\hline
\end{tabular}

Note: The $P$ value is significant if $<0.05$.

Abbreviations: CRP, C-reactive protein; Hb, haemoglobin concentration; $\mathrm{HCT}$, haematocrit value; $\mathrm{LDH}$, lactate dehydrogenase; $\mathrm{MCH}$, mean corpuscular hemoglobin; MCV, mean corpuscular volume; MPV, mean platelet volume; RBCs, red blood cells; RDW, red cell distribution width; TLC, total leukocyte count.

\section{Evaluating the Diagnostic Value of Different Inflammation Indices in COVID-19 Patients}

The ROC curve analysis was performed to determine the ability of the assessed inflammatory indices in identifying patients with COVID-19 infection. The sensitivity, specificity and AUC of NLR were 52.7\%, 82.9\% and 0.649 , respectively at a cut-off $(2.5), \mathrm{P}=0.008$, and those of LMR were $71 \%, 65.9 \%$ and 0.738 , respectively at a cutoff (6). Also, the sensitivity, specificity and AUC of PLR were $67.6 \%, 58.5 \%$ and 0.643 , respectively at a cut-off (118), $\mathrm{P}=0.011$, and those of NLPR were $52.7 \%, 5.1 \%$ 
A

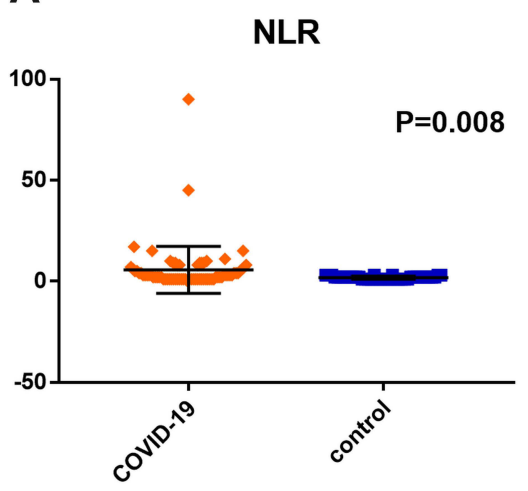

D
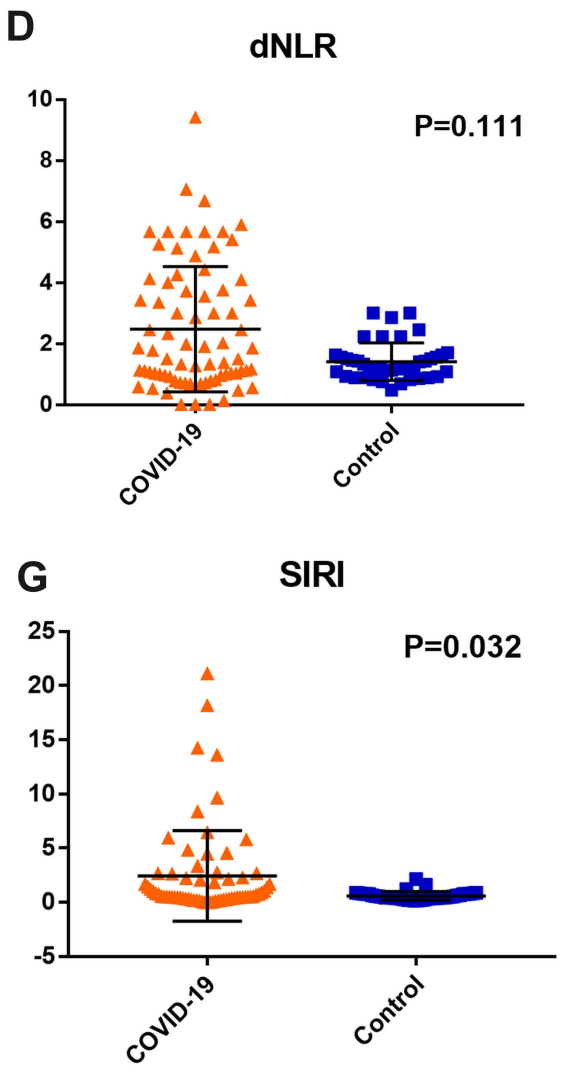

B

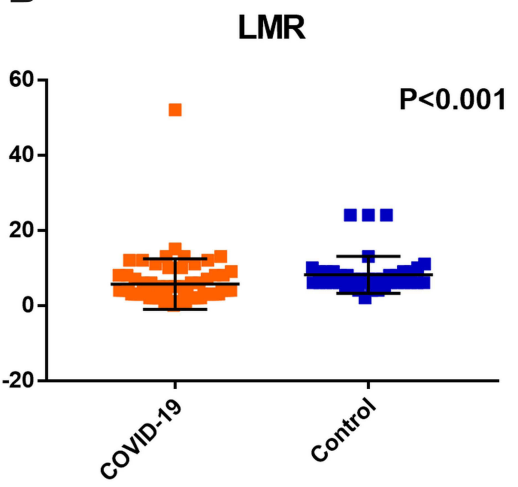

E

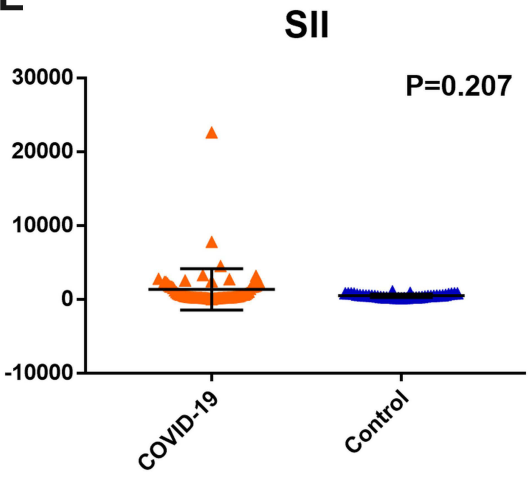

H

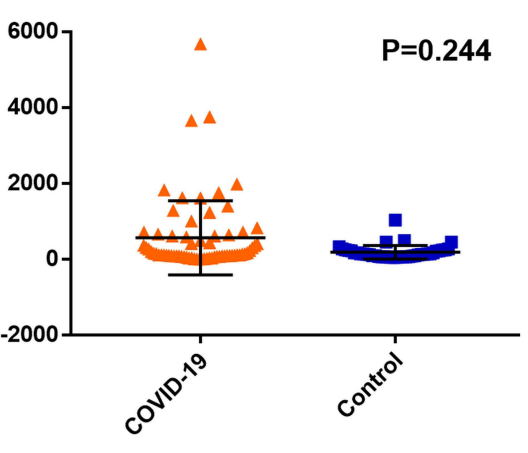

C

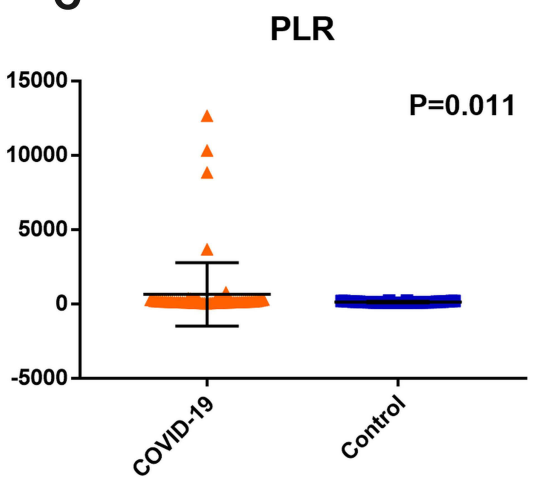

$\mathbf{F}$

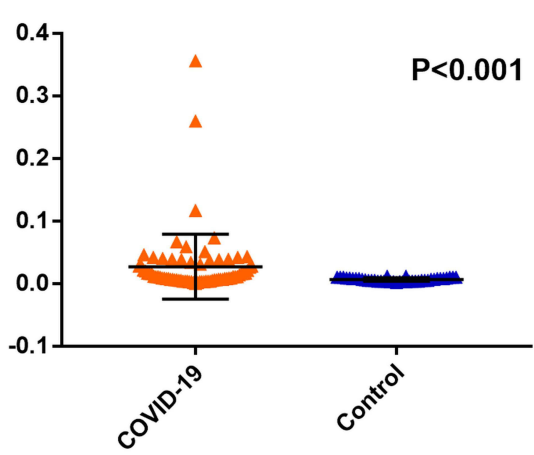

CRP/L

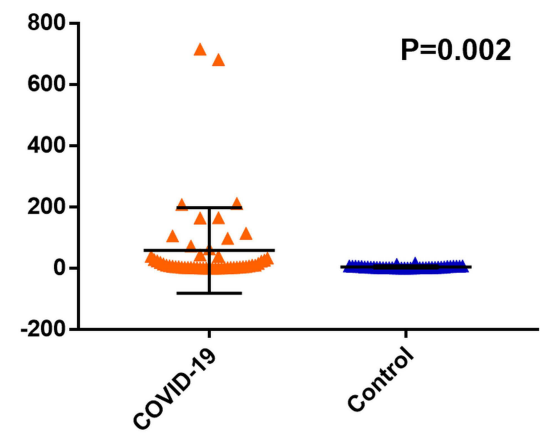

Figure I The results of (A) NLR: the neutrophil to lymphocyte ratio, (B) LMR: lymphocyte to monocyte ratio, (C) PLR: platelet to lymphocyte ratio, (D) dNLR: derived neutrophil to lymphocyte ratio, (E) SIl: systemic inflammation index, (F) NLPR: neutrophil to lymphocyte, platelet ratio, (G) SIRI: systemic inflammation response index, (H) AISI: aggregate index of systemic inflammation, and (I) CRP/L: C-reactive protein to lymphocyte ratio, in the COVID-I9 patients and the control group.

and 0.721 , respectively at a cut-off $(0.0105), \mathrm{P}<0.001$. The SIRI achieved a sensitivity, specificity, and AUC for COVID-19 diagnosis of $47.8 \%, 82.9 \%$ and 0.623 , respectively, at a cut-off (0.8), $\mathrm{P}=0.032$, and $\mathrm{CRP} / \mathrm{L}$ were $50 \%$, $95 \%$ and 0.692 , respectively, at a cut-off (7.6), $\mathrm{P}=0.002$. However, ROC analysis for AISI, dNLR and SII for the diagnosis of COVID-19 patients did not achieve a significant level $(\mathrm{P}=0.244,0.111$ and 0.207 ; respectively, Table 2 and Figure 2).

\section{Univariate and Multivariate Regression Analysis for the Diagnosis of COVID-19 Patients}

Univariate regression analysis showed a significant association of patients' age $>40$ years (OR: 3.397, $\mathrm{P}=0.005$ ), HCT (OR: 3.410, $\mathrm{P}=0.045)$, MCH (OR: 2.847, $\mathrm{P}=0.05$ ), platelet count (OR: 0.290, $\mathrm{P}=0.003$ ), eosinophil count (OR: 0.178, P = 0.003), lymphopenia (OR: 0.075, P < 0.001), CRP (OR: 11.908, P $<0.001)$, and D-dimer (OR: 
Table 2 ROC Curve Analysis for the Diagnostic Value of Different Inflammation Indices in COVID-I9 Patients

\begin{tabular}{|l|c|c|c|c|c|c|c|}
\hline & AUC & Cut-off & Sensitivity & Specificity & \multirow{2}{*}{ P value } & \multicolumn{2}{|c|}{$95 \%$ Confidence Interval } \\
\cline { 3 - 8 } & & & & & \multicolumn{2}{|c|}{ Lower } & Upper \\
\hline NLR & 0.649 & 2.5 & $52.7 \%$ & $82.9 \%$ & 0.008 & 0.550 & 0.747 \\
\hline LMR & 0.738 & 6 & $71 \%$ & $65.9 \%$ & P<0.00I & 0.645 & 0.831 \\
\hline PLR & 0.643 & 118 & $67.6 \%$ & $58.5 \%$ & 0.011 & 0.543 & 0.743 \\
\hline dNLR & 0.590 & 1.7 & $50 \%$ & $82.9 \%$ & 0.111 & 0.489 & 0.690 \\
\hline SII & 0.571 & 807 & $37.8 \%$ & $92.7 \%$ & 0.207 & 0.468 & 0.674 \\
\hline NLPR & 0.721 & 0.0105 & $52.7 \%$ & $95.1 \%$ & $P<0.001$ & 0.631 & 0.811 \\
\hline SIRI & 0.623 & 0.8 & $47.8 \%$ & $82.9 \%$ & 0.032 & 0.520 & 0.725 \\
\hline AISI & 0.567 & 252 & $42 \%$ & $82.9 \%$ & 0.244 & 0.461 & 0.673 \\
\hline CRP/L & 0.692 & 7.6 & $50 \%$ & $95 \%$ & 0.002 & 0.584 & 0.800 \\
\hline
\end{tabular}

Note: The $P$ value is significant if $<0.05$.

Abbreviations: AISI, aggregate index of systemic inflammation; CRP/L, C-reactive protein to lymphocyte ratio; dNLR, derived neutrophil to lymphocyte ratio; LMR, lymphocyte to monocyte ratio; NLPR, neutrophil to lymphocyte; platelet ratio; NLR, the neutrophil to lymphocyte ratio; PLR, platelet to lymphocyte ratio; SII, systemic inflammation index; SIRI, systemic inflammation response index.

12, $\mathrm{P}<0.001$ ), with COVID-19 infection. Regarding the inflammatory indices assessed, it showed that NLR $>2.5$ (OR: 5.412, $\mathrm{P}<0.001)$, LMR $<6$ (OR: 3.828, $\mathrm{P}=0.001)$, PLR $>118$ (OR: 2.412, P =0.028), SII $>807$ (OR: 7.710, $\mathrm{P}=0.002)$, NLPR $>0.011(\mathrm{OR}: 21.729, \mathrm{P}<0.001)$, SIRI $>0.8$ (OR: 4.452, $\mathrm{P}=0.002$ ), AISI $>252$ (OR: 3.521, $\mathrm{P}=$ 0.009), and CRP/L >7.6 (OR: 19, $\mathrm{P}<0.001$ ) associated significantly with COVID-19 infection, while dNLR $>1.7$ had OR of 1.509 at $\mathrm{P}=0.291$.

Multivariate regression analysis showed that HCT $>38.5$ (OR: 33.148, $\mathrm{P}=0.029$ ), NLPR $>0.011$ (OR: 38.751, $\mathrm{P}=0.014)$, and $\mathrm{CRP} / \mathrm{L}>7.6(\mathrm{OR}: 7.604, \mathrm{P}=0.022)$ are considered independent diagnostic factors for COVID-19 infection (Table 3).

\section{Discussion}

COVID-19 is a highly infectious pandemic disease, affecting more than 200 countries with a variable presentation from mild to critically severe symptoms. Therefore, it is very important to search for an early, rapid, simple and reliable test for supporting the clinical in the diagnosis of COVID-19 infection to start treatment, till confirmation by other available methods.

In the current study, we tried to assess most of the laboratory parameters and inflammatory indices used in the literature for the provisional diagnosis of COVID-19 infection. The present data demonstrated that there was a significant increase in the NLR $>2.5$, PLR $>118$, NLPR $>0.0105$, SIRI
$>0.8$ and $\mathrm{CRP} / \mathrm{L}>7.6$, while a significant decrease in LMR $<6$, in COVID-19 patients compared to the control group. Additionally, univariate analysis showed that SII and AISI were significantly associated with COVID-19 infection. However, there was no significant difference between COVID-19 patients and the control group regarding the values of dNLR. These data are consistent with Seyit et al, ${ }^{23}$ who found that NLR and PLR ratios were significantly increased in patients infected with COVID-19 compared to non-infected counterparts. Similarly, Sun et $\mathrm{a}^{24}$ concluded that NLR, LMR and PLR had a high diagnostic value for COVID-19 patients based on a comparative study between infected and non-infected patients from China. In addition, many published studies reported the significant role of NLR in the diagnosis of COVID-19 patients. $^{25,26}$ Other studies reported the association of NLR with the severity of COVID-19 infection. ${ }^{27-30}$ Moreover, Song et $\mathrm{al}^{29}$ concluded that NLR could be used as a screening marker to identify high-risk patients at admission to the hospital. On the other hand, Chandler et $\mathrm{a}^{30}$ reported that NLR varied according to the disease severity, but it did not differ between COVID-19 patients and healthy individuals.

For more confirmation, ROC analysis was performed for the assessed inflammatory indices to identify COVID19 patients. The AUC for LMR, NLPR, CRP/L, NLR, PLR, SIRI, dNLR, SII, and AISI, were 0.738, 0.721, $0.692,0.649,0.643,0.623,0.590,0.571$ and 0.567 , respectively. It revealed that the LMR achieved the highest 
A

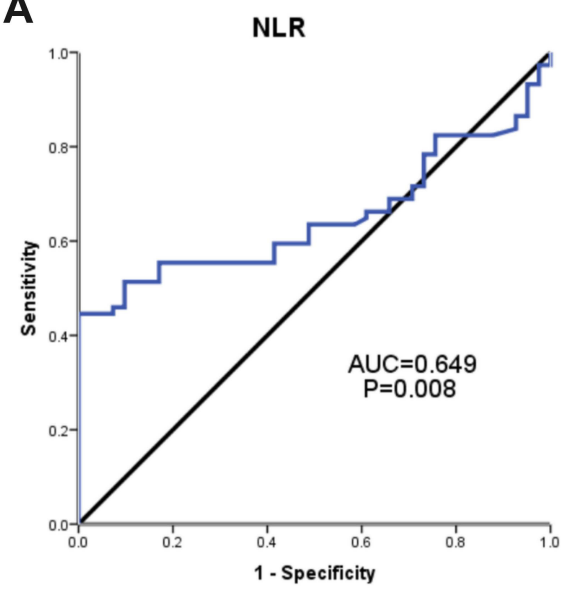

D

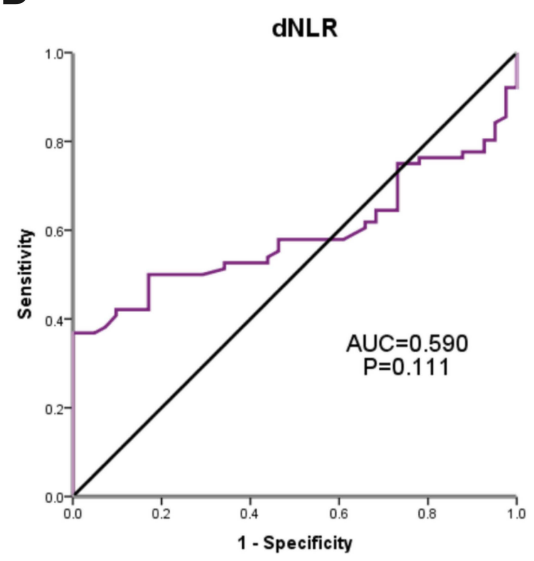

G

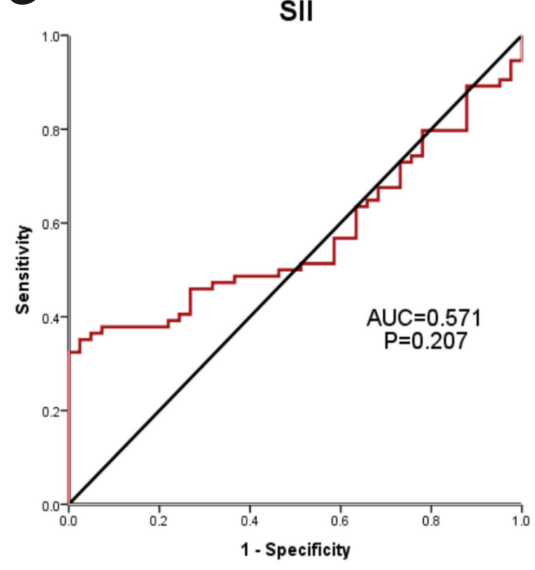

B

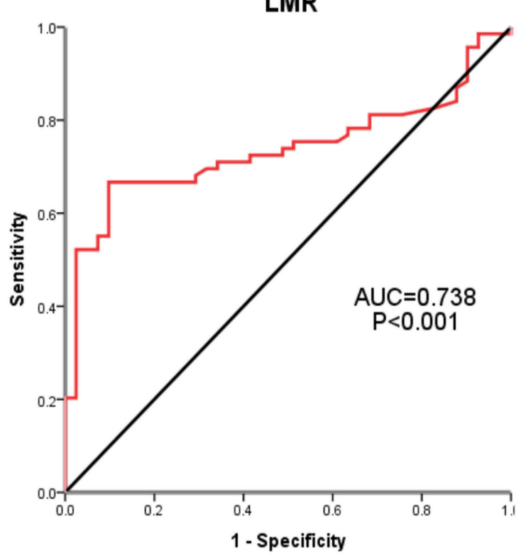

E

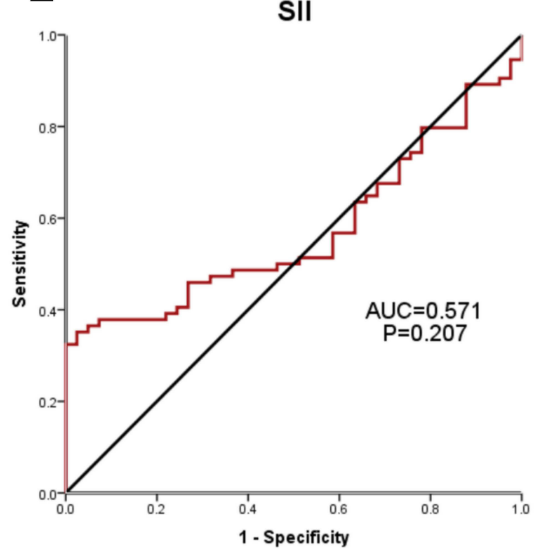

H

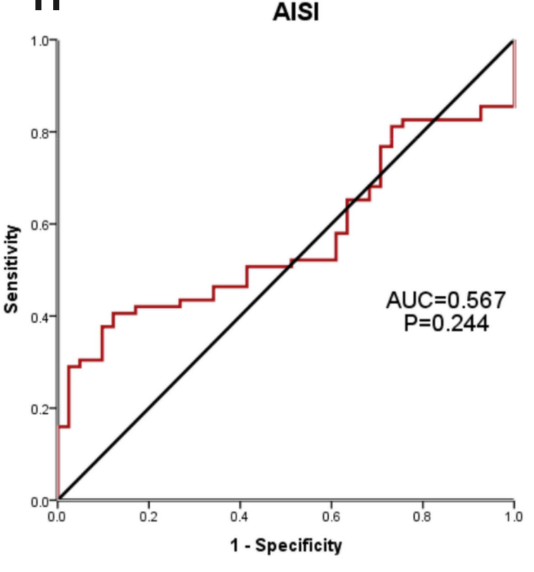

C

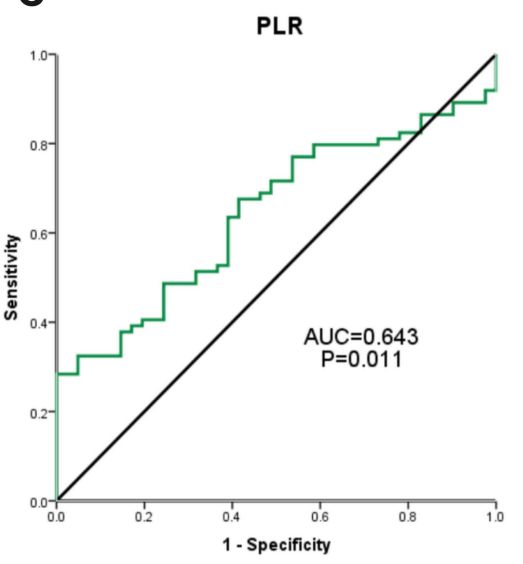

F

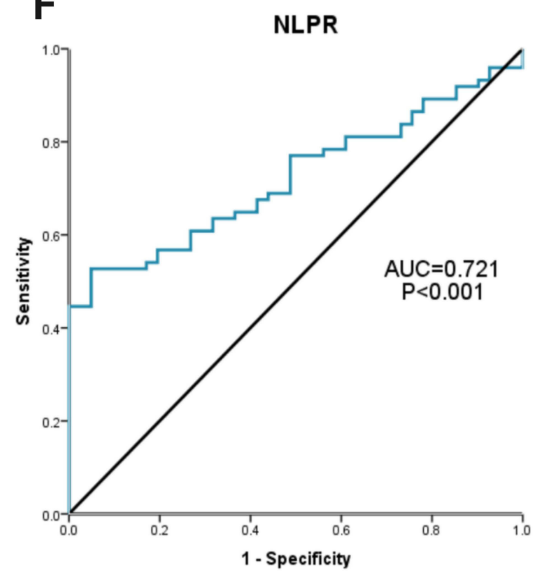

I

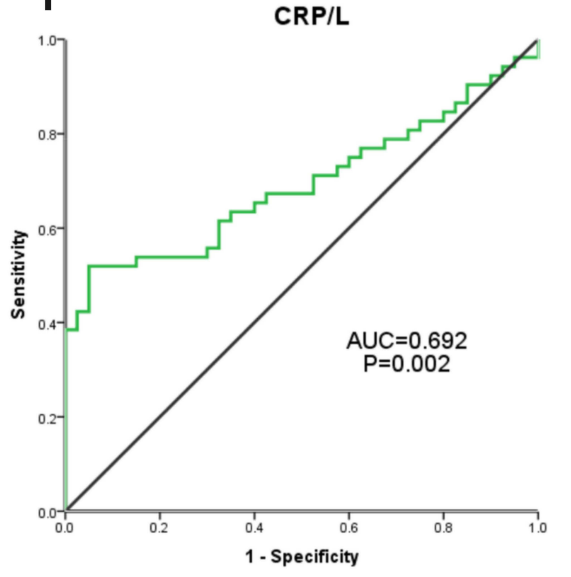

Figure 2 The ROC curve analysis for (A) NLR: the neutrophil to lymphocyte ratio, (B) LMR: lymphocyte to monocyte ratio, (C) PLR: platelet to lymphocyte ratio, (D) dNLR: derived neutrophil to lymphocyte ratio, (E) SIl: systemic inflammation index, (F) NLPR: neutrophil to lymphocyte, platelet ratio, (G) SIRI: systemic inflammation response index, (H) AISI: aggregate index of systemic inflammation, and (I) CRP/L: C-reactive protein to lymphocyte ratio, in the diagnosis of COVID-I9 patients.

sensitivity $(71 \%$, cutoff $<6)$, followed by the PLR $(67.6 \%$, cutoff $>118$ ), while NLPR achieved the highest specificity (95.1\%, cutoff $>0.0105)$ followed by CRP/L $(95 \%$, cutoff >7.6). In line with these results, Zhang and his team reported that increasing NLR and SII values were observed in $94.5 \%$ and $89.2 \%$ of COVID-19 patients at diagnosis, respectively. ${ }^{31}$ Also, Usul et al ${ }^{15}$ concluded that NLR and SII could be used in COVID-19 diagnosis. In addition, SII is considered a predictive biomarker for inhospital mortality and ICU admission. ${ }^{32}$ 
Table 3 Univariate and Multivariate Analysis for the Diagnosis of COVID-19 Patients

\begin{tabular}{|c|c|c|c|c|c|c|c|c|}
\hline & \multicolumn{4}{|c|}{ Univariate Analysis } & \multicolumn{4}{|c|}{ Multivariate Analysis } \\
\hline & \multirow{2}{*}{$\begin{array}{l}\text { Odds Ratio } \\
\text { (OR) }\end{array}$} & \multicolumn{2}{|c|}{ 95\% C.I. } & \multirow[t]{2}{*}{$P$ value } & \multirow{2}{*}{$\begin{array}{l}\text { Odds Ratio } \\
\text { (OR) }\end{array}$} & \multicolumn{2}{|c|}{ 95\% C.I. } & \multirow[t]{2}{*}{$P$ value } \\
\hline & & Lower & Upper & & & Lower & Upper & \\
\hline Age $(>40)$ & 3.397 & 1.454 & 7.937 & 0.005 & 5.697 & 0.487 & 66.653 & 0.166 \\
\hline $\mathrm{Hb}(>12.6) \mathrm{g} / \mathrm{dl}$ & 0.532 & 0.243 & 1.167 & 0.115 & & & & \\
\hline RBCs $(>4.6) 10^{6} / \mathrm{ul}$ & 2.049 & 0.713 & 5.890 & 0.183 & & & & \\
\hline HCT $(>38.5) \%$ & 3.410 & 1.030 & 11.296 & 0.045 & 30.73 & 0.760 & 1243.09 & 0.070 \\
\hline MCV $(<82.4) \mathrm{fL}$ & 1.732 & 0.683 & 4.394 & 0.247 & & & & \\
\hline $\mathrm{MCH}(>27) \mathrm{Pg}$ & 2.847 & 0.999 & 8.114 & 0.050 & 3.228 & 0.216 & 48.202 & 0.395 \\
\hline RDW (>13.6) \% & 0.500 & 0.115 & 2.175 & 0.355 & & & & \\
\hline Platelets $(>227) \times 10^{9} / \mathrm{L}$ & 0.290 & 0.127 & 0.661 & 0.003 & 0.045 & 0.001 & 1.505 & 0.083 \\
\hline $\operatorname{TLC}(>6.5) \times 10^{9} / \mathrm{L}$ & 1.065 & 0.497 & 2.283 & 0.872 & & & & \\
\hline Neutrophil $(>2.9) 10^{3} / \mathrm{ul}$ & 0.453 & 0.198 & 1.034 & 0.060 & & & & \\
\hline Segmented\% (>60) & 2.000 & 0.649 & 6.166 & 0.228 & & & & \\
\hline $\begin{array}{l}\text { Eosinophil }(>0.05) 10^{3} / \\
\text { ul }\end{array}$ & 0.178 & 0.056 & 0.560 & 0.003 & 0.030 & 0.001 & 1.629 & 0.085 \\
\hline Basophil $(>0) 10^{3} / \mathrm{ul}$ & 1.646 & 0.683 & 3.968 & 0.267 & & & & \\
\hline $\begin{array}{l}\text { Lymphocytes (>I.5) } 10^{3} / \\
\text { ul }\end{array}$ & 0.075 & 0.021 & 0.264 & $P<0.001$ & 0.312 & 0.007 & 13.647 & 0.546 \\
\hline $\operatorname{CRP}(>13.1) \mathrm{mg} / \mathrm{L}$ & 11.908 & 3.291 & 43.090 & $P<0.001$ & 8.543 & 0.207 & 352.901 & 0.259 \\
\hline Ferritin $(>200) \mathrm{ng} / \mathrm{L}$ & 7.619 & 0.872 & 66.541 & 0.066 & & & & \\
\hline D-dimer $(>0.33) \mathrm{ng} / \mathrm{mL}$ & 12.000 & 3.140 & 45.855 & $P<0.001$ & 3.721 & 0.049 & 283.207 & 0.552 \\
\hline NLR $(>2.5)$ & 5.412 & 2.130 & 13.755 & $P<0.00$ I & 0.158 & 0.009 & 2.932 & 0.216 \\
\hline $\operatorname{LMR}(<6)$ & 3.828 & 1.694 & 8.648 & 0.001 & 0.360 & 0.097 & 1.335 & 0.127 \\
\hline PLR $(>\mid 18)$ & 2.412 & 1.102 & 5.280 & 0.028 & 0.659 & 0.191 & 2.272 & 0.509 \\
\hline $\mathrm{dNLR}(>1.7)$ & 1.509 & 0.703 & 3.237 & 0.291 & & & & \\
\hline SII (>807) & 7.710 & 2.174 & 27.340 & 0.002 & 3.897 & 0.269 & 56.428 & 0.318 \\
\hline NLPR $(>0.011)$ & 21.729 & 4.885 & 96.651 & $P<0.001$ & 38.751 & 2.080 & 722.060 & 0.014 \\
\hline SIRI $(>0.8)$ & 4.452 & 1.738 & 11.406 & 0.002 & 6.68 & 0.000 & & 0.999 \\
\hline AISI (>252) & 3.521 & $1.37 \mid$ & 9.047 & 0.009 & 0.884 & 0.000 & & 0.999 \\
\hline CRP/L (>7.6) & 19.000 & 4.146 & 87.070 & $P<0.001$ & 7.604 & 1.338 & 43.224 & 0.022 \\
\hline
\end{tabular}

Note: The $P$ value is significant if $<0.05$.

Abbreviations: AISI, aggregate index of systemic inflammation; CRP, C-reactive protein; CRP/L, CRP to lymphocyte ratio; dNLR, derived neutrophil to lymphocyte ratio; $\mathrm{Hb}$, haemoglobin concentration; HCT, haematocrit value; $\mathrm{LDH}$, lactate dehydrogenase; $M C H$, mean corpuscular hemoglobin; MCV, mean corpuscular volume; LMR, lymphocyte to monocyte ratio; NLPR, neutrophil to lymphocyte; platelet ratio; NLR, the neutrophil to lymphocyte ratio; PLR, platelet to lymphocyte ratio; RBCs, red blood cells; RDW, red cell distribution width; SII, systemic inflammation index; SIRI, systemic inflammation response index; TLC, total leukocyte count. 
Moreover, our data demonstrated that NLR showed a sensitivity of $52.7 \%$ and specificity of $82.9 \%$ at a cutoff 2.5 for the diagnosis of COVID-19 positive patients. In this concern, Zhang et $\mathrm{al}^{31}$ demonstrated that $94 \%$ of the assessed COVID-19 patients had increased NLR $>5$. Also, Sun et $\mathrm{al}^{24}$ found that NLR had a sensitivity of $74.07 \%$ and specificity of $89.89 \%$ at a cut-off 4.5 , while the results of Seyit et $\mathrm{al}^{23}$ showed that NLR had $70 \%$ sensitivity and $46 \%$ specificity at a cut-off 1.81 . Though NLR is a widely used inflammatory marker, it is not sufficient alone for the detection of COVID-19 infection. ${ }^{33}$ Also, it is difficult to detect an exact cut-off value, as it had been demonstrated that the cut-off varies according to the population and race. ${ }^{34}$ So, combining the assessed inflammatory indices together with different sensitivity and specificity levels could add value to COVID-19 diagnosis.

Furthermore, the univariate analysis performed in the present study showed that COVID-19 infection is significantly associated with increasing patients' age, HCT, $\mathrm{MCH}, \mathrm{CRP}$ and D-dimer, in addition to thrombocytopenia, eosinopenia and finally lymphopenia.

These data are consistent with many published studies reported the significant association of lymphopenia, eosinopenia, thrombocytopenia and increased CRP with COVID-19 disease. ${ }^{16,24,25,31,35}$ Moreover, it had been reported that lymphopenia and eosinopenia were associated with the severity of COVID-19 disease course and mortality. ${ }^{36-38}$

The neutropenia was reported in some studies in COVID-19 patients, ${ }^{16,39}$ while others observed neutrophilia. ${ }^{31,40}$ However, our results did not show a significant change in the neutrophil count between patients and control subjects. These data are in agreement with Khartabil et $\mathrm{al}^{25}$ who indicated in their review that neutrophil count was mostly normal in non-severe cases, and it increased in severe cases.

Interestingly, the present study showed that patients with COVID-19 infection had significantly increased levels of $\mathrm{Hb}, \mathrm{MCH}$ and HCT. These results are consistent with $\mathrm{Yu}$ et al, ${ }^{14}$ who observed a significant increased MCH level in COVID-19 patients compared to healthy individuals. Similarly, Usul et al ${ }^{16}$ reported increased $\mathrm{Hb}$ concentration in patients with COVID-19 infection compared to control group. However, Sun et $\mathrm{al}^{24}$ reported lower $\mathrm{Hb}$ level in COVID-19 patients. Actually, the patients included in this study had mostly mild-tomoderate infection, as inflammation can affect erythrocytes maturation, and therefore decreased hemoglobin production might occur in severe COVID-19 cases, ${ }^{41}$ or it might be due to direct infection of the precursor RBCs by the virus itself. $^{42}$ Moreover, Hariyanto and Kurniawan concluded in their letter that anemia is associated with severe COVID-19 infection. ${ }^{43}$

Finally, the current study demonstrated that NLPR $>0.011$ and $\mathrm{CRP} / \mathrm{L}>7.6$ are considered possible independent diagnostic factors for COVID-19 infection. In line with our results, several studies reported the significant role of CRP/L as a prognostic factor for COVID-19 severity. ${ }^{44,45}$

In conclusion, hemocytometric evaluation, especially changes in lymphocyte and platelet count, with their derived inflammatory indices could assist clinicians in the diagnosis of COVID-19 infection, in addition to their reported role in the prediction of COVID-19 severity. Many indices including NLR $>2.5$, PLR $>118$, NLPR $>0.0105$, SIRI $>0.8, \mathrm{CRP} / \mathrm{L}>7.6$, and $\mathrm{LMR}<6$ have important roles in the diagnosis and prognosis of COVID-19 patients. The NLPR and CRPL could be potential diagnostic factors for COVID-19. However, the limitation of this study is the small number of patients involved, in addition, they were recruited from a single institute. Therefore, these data should be validated on a larger number of patients with different degrees of disease severity. Also, to assess the association of these indices with the patients' outcomes.

\section{Disclosure}

The authors report no conflicts of interest in this work.

\section{References}

1. Gorbalenya AE, Baker SC, Baric RS, et al. Severe acute respiratory syndrome-related coronavirus: the species and its viruses - a statement of the coronavirus study group. bioRxiv. 2020;2020. doi:10.1101/ 2020.02.07.937862

2. Huang C, Wang Y, Li X, et al. Clinical features of patients infected with 2019 novel coronavirus in Wuhan, China. Lancet. 2020;395 (10223):497-506. doi:10.1016/S0140-6736(20)30183-5

3. Mehta P, McAuley DF, Brown M, Sanchez E, Tattersall RS, Manson JJ; HLH Across Speciality Collaboration, UK. COVID-19: consider cytokine storm syndromes and immunosuppression. Lancet. 2020;395(10229):1033-1034. doi:10.1016/S0140-6736(20)30628-0

4. Ciceri F, Beretta L, Scandroglio AM, et al. Microvascular COVID-19 lung vessels obstructive thromboinflammatory syndrome (MicroCLOTS): an atypical acute respiratory distress syndrome working hypothesis. Crit Care Resusc. 2020;22(2):95-97.

5. Xiang N, Havers F, Chen T, et al. Use of national pneumonia surveillance to describe influenza $\mathrm{A}(\mathrm{H} 7 \mathrm{~N} 9)$ virus epidemiology, China, 2004-2013. Emerg Infect Dis. 2013;19(11):1784-1790. doi:10.3201/ eid1911.130865

6. Güneş M, Büyükgöl H. Relationship between generalized epileptic seizure and neutrophil/lymphocyte ratio, platelet/lymphocyte ratio, and neutrophil mediated inflammation. Int J Neurosci. 2020;130 (11):1095-1100. doi:10.1080/00207454.2020.1722662 
7. Qu R, Ling Y, Zhang YH, et al. Platelet-to-lymphocyte ratio is associated with prognosis in patients with coronavirus disease-19. J Med Virol. 2020;92(9):1533-1541. doi:10.1002/jmv.25767

8. Jenne CN, Kubes P. Platelets in inflammation and infection. Platelets. 2015;26(4):286-292. doi:10.3109/09537104.2015.1010441

9. Lazzaroni MG, Piantoni S, Masneri S, et al. Coagulation dysfunction in COVID-19: the interplay between inflammation, viral infection and the coagulation system. Blood Rev. 2021;46:100745. doi:10.1016/j. blre.2020.100745

10. Wool GD, Miller JL. The Impact of COVID-19 disease on platelets and coagulation. Pathobiology. 2021;88(1):15-27. doi:10.1159/000512007

11. Ulinici M, Covantev S, Wingfield-Digby J, Beloukas A, Mathioudakis AG, Corlateanu A. Screening, diagnostic and prognostic tests for COVID-19: a comprehensive review. Life (Basel). 2021;11(6):561.

12. Hong X, Cui B, Wang M, Yang Z, Wang L, Xu Q. Systemic immune-inflammation index, based on platelet counts and neutrophil-lymphocyte ratio, is useful for predicting prognosis in small cell lung cancer. Tohoku J Exp Med. 2015;236(4):297-304. doi:10.1620/tjem.236.297

13. Ying HQ, Deng QW, He BS, et al. Suppressed T cell-mediated immunity in patients with COVID-19: a clinical retrospective study in Wuhan, China. J Infect. 2020;81(1):e51-e60. doi:10.1016/j. jinf.2020.04.012

14. Yu H, Yu H, Yu H, et al. Total protein as a biomarker for predicting coronavirus disease-2019 pneumonia. Lancet. 2020;2020:20.

15. Qin C, Zhou L, Hu Z, et al. Dysregulation of immune response in patients with COVID-19 in Wuhan, China. Clin Infect Dis. 2020;71:762.

16. Usul E, Şan İ, Bekgöz B, Şahin A. Role of hematological parameters in COVID-19 patients in the emergency room. Biomark Med. 2020;14(13):1207-1215. doi:10.2217/bmm-2020-0317

17. Fois AG, Paliogiannis P, Scano V, et al. The systemic inflammation index on admission predicts in-hospital mortality in COVID-19 patients. Molecules. 2020;25(23):5725. doi:10.3390/molecules25235725

18. Chau VQ, Oliveros E, Mahmood K, et al. The imperfect cytokine storm: severe COVID-19 with ARDS in a patient on durable LVAD support. JACC Case Rep. 2020;2(9):1315-1320. doi:10.1016/j. jaccas.2020.04.001

19. Cossarizza A, Gibellini L, De Biasi S, et al. Handling and processing of blood specimens from patients with COVID-19 for safe studies on cell phenotype and cytokine storm. Cytometry A. 2020;97 (7):668-673. doi:10.1002/cyto.a.24009

20. Ying HQ, Deng QW, He BS, et al. The prognostic value of preoperative NLR, d-NLR, PLR and LMR for predicting clinical outcome in surgical colorectal cancer patients. Medical Oncology. 2014;31 (12):305. doi:10.1007/s12032-014-0305-0

21. Acar E, Demir A, Yıldırım B, Kaya MG, Gökçek K. The role of hemogram parameters and $\mathrm{C}$-reactive protein in predicting mortality in COVID-19 infection. Int J Clin Pract. 2021;75(7):e14256. doi:10.1111/ijcp.14256

22. World Health Organization. Clinical Management of Severe Acute Respiratory Infection When Middle East Respiratory Syndrome Coronavirus (MERS-Cov) Infection is Suspected: Interim Guidance. World Health Organization; 2019.

23. Seyit M, Avci E, Nar R, et al. Neutrophil to lymphocyte ratio, lymphocyte to monocyte ratio and platelet to lymphocyte ratio to predict the severity of COVID-19. Am J Emerg Med. 2021;45:569. doi:10.1016/j.ajem.2020.12.069

24. Sun S, Cai X, Wang H, et al. Abnormalities of peripheral blood system in patients with COVID-19 in Wenzhou, China. Clin Chim Acta. 2020;507:174-180. doi:10.1016/j.cca.2020.04.024

25. Khartabil TA, Russcher H, van der Ven A, de Rijke YB. A summary of the diagnostic and prognostic value of hemocytometry markers in COVID-19 patients. Crit Rev Clin Lab Sci. 2020;57(6):415-431. doi:10.1080/10408363.2020.1774736
26. Feng Z, Yu Q, Yao S, et al. Early prediction of disease progression in 2019 novel coronavirus pneumonia patients outside Wuhan with CT and clinical characteristics. medRxiv. 2020;11:4968.

27. Yang A, Liu J, Tao W, et al. The diagnostic and predictive role of in COVID-19 patients NLR, d-NLR and PLR. Int Immunopharmacol. 2020;84:106504. doi:10.1016/j.intimp.2020.106504

28. Yang P, Ding Y, Xu Z, et al. Epidemiological and clinical features of COVID-19 patients with and without pneumonia in Beijing, China. medRxiv. 2020. doi:10.1101/2020.02.28.20028068

29. Song C-Y, Xu J, He J-Q, et al. COVID-19 early warning score: a multi-parameter screening tool to identify highly suspected patients. medRxiv. 2020. doi:10.1101/2020.03.05.20031906

30. Chandler CM, Reid MC, Cherian S, Sabath DE, Edlefsen KL. Comparison of blood counts and markers of inflammation and coagulation in patients with and without COVID-19 presenting to the Emergency Department in Seattle, WA. Am J Clin Pathol. 2021;156 (2):185-197. doi:10.1093/ajcp/aqab052

31. Zhang B, Zhou X, Qiu Y, et al. Clinical characteristics of 82 cases of death from COVID-19. PLoS One. 2020;15(7):e0235458. doi:10.1371/journal.pone.0235458

32. Nalbant A, Demirci T, Kaya T, Aydın A, Altındiş M, Güçlü E. Can prognostic nutritional index and systemic immune-inflammatory index predict disease severity in COVID-19? Int $J$ Clin Pract. 2021; $17:$ e14544.

33. Carpio-Orantes LD, García-Méndez S, Hernández-Hernández SN. Neutrophil-to-lymphocyte ratio, platelet-to-lymphocyte ratio and systemic immune-inflammation index in patients with COVID-19-associated pneumonia. Gac Med Mex. 2020;156 (6):527-531.

34. Azab B, Camacho-Rivera M, Taioli E. Average values and racial differences of neutrophil lymphocyte ratio among a nationally representative sample of United States subjects. PLoS One. 2014;9(11): e112361. doi:10.1371/journal.pone.0112361

35. Fu L, Wang B, Yuan T, et al. Clinical characteristics of coronavirus disease 2019 (COVID-19) in China: a systematic review and meta-analysis. $J$ Infect. 2020;80(6):656-665. doi:10.1016/j. jinf.2020.03.041

36. Du Y, Tu L, Zhu P, et al. Clinical features of 85 fatal cases of COVID-19 from Wuhan. A retrospective observational study. Am J Respir Crit Care Med. 2020;201(11):1372-1379. doi:10.1164/ rccm.202003-0543OC

37. Tan L, Wang Q, Zhang D, et al. Lymphopenia predicts disease severity of COVID-19: a descriptive and predictive study. Signal Transduct Target Ther. 2020;5(1):33. doi:10.1038/s41392-0200148-4

38. Lindsley AW, Schwartz JT, Rothenberg ME. Eosinophil responses during COVID-19 infections and coronavirus vaccination. J Allergy Clin Immunol. 2020;146(1):1-7. doi:10.1016/j.jaci.2020.04.021

39. Ai JW, Zhang $\mathrm{HC}, \mathrm{Xu} \mathrm{T}$, et al. Optimizing diagnostic strategy for novel coronavirus pneumonia, a multi-center study in Eastern China. MedRxiv. 2020. doi:10.1101/2020.02.13.20022673

40. Lo IL, Lio CF, Cheong HH, et al. Evaluation of SARS-CoV-2 RNA shedding in clinical specimens and clinical characteristics of 10 patients with COVID-19 in Macau. Int J Biol Sci. 2020;16 (10):1698-1707. doi:10.7150/ijbs.45357

41. McCranor BJ, Kim MJ, Cruz NM, et al. Interleukin-6 directly impairs the erythroid development of human TF1 erythroleukemic cells. Blood Cells Mol Dis. 2014;52(2-3):126-133. doi:10.1016/j. bcmd.2013.09.004

42. Yang M, Li CK, Li K, et al. Hematological findings in SARS patients and possible mechanisms (review). Int J Mol Med. 2004;14 (2):311-315.

43. Hariyanto TI, Kurniawan A. Anemia is associated with severe coronavirus disease 2019 (COVID-19) infection. Transfus Apher Sci. 2020;59(6):102926. doi:10.1016/j.transci.2020.102926 
44. Yang M, Chen X, Xu Y, Retrospective A. Study of the C-reactive protein to lymphocyte ratio and disease severity in 108 patients with early COVID-19 pneumonia from January to March 2020 in Wuhan, China. Med Sci Monit. 2020;26:e926393. doi:10.12659/MSM.926393
45. Xu JB, Xu C, Zhang RB, et al. Associations of procalcitonin, $\mathrm{C}$-reaction protein and neutrophil-to-lymphocyte ratio with mortality in hospitalized COVID-19 patients in China. Sci Rep. 2020;10 (1):15058. doi:10.1038/s41598-020-72164-7

\section{Publish your work in this journal}

The International Journal of General Medicine is an international, peer-reviewed open-access journal that focuses on general and internal medicine, pathogenesis, epidemiology, diagnosis, monitoring and treatment protocols. The journal is characterized by the rapid reporting of reviews, original research and clinical studies across all disease areas. The manuscript management system is completely online and includes a very quick and fair peer-review system, which is all easy to use. Visit http://www.dovepress.com/ testimonials.php to read real quotes from published authors.

Submit your manuscript here: https://www.dovepress.com/international-journal-of-general-medicine-journal 